\title{
A.R UN MOVIMIENTO ÉTNICO-RELIGIOSO EN EL ÁREA DE COPÁN (HONDURAS): LA IGLESIA MILENARISTA DEL SIGLO NUEVO Ignacio R. Mena Cabezas ${ }^{1}$ y Lázaro H. Flores Mejía ${ }^{2}$
}

${ }^{1}$ Doctor en Antropología Social. Profesor de Filosofía. IES Macarena. Sevilla. Av. Concejal Jiménez Becerril, 10, 2. 41009 Sevilla. (España) E-mail: menade65@yahoo.es.

${ }^{2}$ Profesor Titular de Ciencias Sociales y Antropología. Universidad Pedagógica Nacional Francisco Morazán. Tegucigalpa. (Honduras). E-mail: patacaco@latinmail.com

\begin{abstract}
Resumen
La aparición de un movimiento mesiánico y milenarista en el área chortí del norte de Honduras junto con los procesos de etnogénesis indígenas emprendidos sirven de referente etnográfico para analizar y reflexionar sobre las relaciones entre fenómenos sociales, religiosos, políticos e identitarios en el contexto de la globalización en Honduras. Las reivindicaciones económicas, sociales, educativas, sanitarias o las reclamaciones de tierras se reelaboran desde perspectivas étnicas mayas, de esta forma adquieren un valor simbólico privilegiado. Las tensiones, conflictos y contradicciones del movimiento indígena se han extendido al campo religioso. En este contexto surge la Iglesia del Nuevo Siglo o Nuevo Katum. El trabajo plantea una interpretación de los fenómenos religiosos como motores de cambio y transformación, algo que es, por lo demás, mucho más cercano a la experiencia concreta y personal de los agentes sociales. La reelaboración que lleva a cabo este movimiento de la realidad económica, social e ideológica, van mucho más allá de una mera interpretación profética del mundo al dotar a los seguidores chortís de estrategias prácticas de relación eficaz con el mundo y de transformación de las relaciones tanto intra como interétnicas.
\end{abstract}

\section{Palabras clave}

Movimientos étnicos, religión, milenarismo, mayas, chortis.

\begin{abstract}
The emergence of a millenarist and messianic movement in the Chorti area of Northern Honduras together with the processes of native ethnogenesis provides an ethnographic framework to analyse and discuss the relationships among the social, religious, political and identity phenomena in the context of globalization in Honduras. The economical, social, educational, public health as well as land claims are worked out from Maya ethnic perspectives, thus acquiring a relevant symbolic value. The tensions, conflicts and contradictions of this native movement have spread to the religious level. In this context, the church of the Nuevo Siglo, of the Nuevo Katum has risen. This paper poses an interpretation of the religious phenomena as engines for change and transformation which is, moreover, much closer to the daily and personal experience of the social agents. The remake carried out by this movement in the economical, social and ideological level go beyond a simple prophetic
\end{abstract}


interpretation of the world by supplying their Chorti followers with practical strategies of effective link with the world and of transformation of the intra and interethnic relations.

Key words

Ethnic Movements, Religion, Millenarism, Mayas, Chortis

\section{Introducción}

L a pluralidad, complejidad y vitalidad de los movimientos socio-religiosos en todo el mundo, y en el área centroamericana en particular, constituye uno de los fenómenos actuales más interesantes para las ciencias sociales. La extensión, desarrollo y consolidación del proceso de globalización económica, política y cultural mundial, se ha producido de manera entrelazada con diferentes acontecimientos en las últimas décadas como: los fenómenos migratorios generalizados, la revitalización de los nacionalismos, la reafirmación de las identidades étnicas o religiosas, las diferentes formas de integrismo, los procesos de hibridación cultural, la disolución de las fronteras religiosas, milenarismos, etc, que han terminado por cuestionar las tesis de la secularización y racionalismo modernos. Todo parece indicar que es precisamente la modernización y la secularización lo que está generando la creatividad religiosa (Beyer, 1994). Honduras no ha estado al margen de esos procesos globales. El campo religioso hondureño se encuentra, pues, fragmentado y sometido a las irrupciones, tensiones y contradicciones de nuevos agentes que compiten por el monopolio de la oferta y demanda de bienes simbólicos de salvación ${ }^{1}$.

En Honduras conviven instituciones y grupos jerárquicos inmovilistas junto a la tendencia acusada de paulatina fragmentación del catolicismo universalista en grupos más reducidos y cohesionados: carismáticos, catecumenales, comunidades de base, grupos seguidores de la teología de la liberación o de la pastoral indígena, congregaciones fundamentalistas, etc. Por otro lado, la extensión y pluralidad de formas protestantes está minando la tradicional supremacía católica hasta límites insospechados, además, frente al estancamiento de las iglesias protestantes históricas (anteriores al siglo XIX), las iglesias evangélicas y pentecostales en su

\footnotetext{
${ }^{1}$ Sobre el concepto de campo religioso y competencia por el mercado simbólico el autor se remite a los textos de Pierre Bourdieu (1971 y 1993). Una reflexión actual sobre las teorías antropológicas de la religión y la pluralidad religiosa puede verse en Manuela Cantón (2001) y en B. Morris (1995). 
complejo repertorio denominacional, son las que mejor se han adaptado a las condiciones de pobreza, desestructuración política y mundialización de la economía ${ }^{2}$.

Pero esta efervescencia y revitalismo religioso (que supera el ámbito de las iglesias como instituciones) ha calado también en los movimientos sociales indígenas hondureños. Los procesos de resignificación étnica y los renacimientos comunitarios son, hasta cierto punto y de forma paradójica, consecuencia de las situaciones generadas por los mismos contextos mundiales de globalización. Los grupos indígenas ponen en marcha "nuevas" estrategias identitarias que no pueden entenderse al margen de procesos muchos más amplios. Las pervivencias prehispánicas que conformaron formas sincréticas con el catolicismo han acabado por despertar y comenzar a desligarse de la costumbre, entendida como el resultado ritual de la negociación e intercambio entre los universos simbólicos precolombinos y católicos europeos. Y pese a los esfuerzos de la Iglesia Católica, en su vertiente más progresista de la teología de la liberación, hacia la conformación de una Teología India como religión de los oprimidos en sus particularidades étnicas ${ }^{3}$, algunos movimientos indios han acabado por desarrollar respuestas y estrategias nativistas, revivalistas y milenaristas para enfrentarse a la realidad y dar significado a los conflictos del presente. Así pues, entendemos que esta revitalización religiosa ha sido paralela al despertar de los movimientos sociales, políticos, étnicos y de género, en un país que se mantuvo con relativa distancia (aunque bajo control neocolonial) de los movimientos revolucionarios de los años sesenta y setenta centroamericanos. En efecto, la movilización política de los grupos étnicos ha generado la aparición de "nuevos" agentes políticos que reivindican derechos en un contexto mundial cada vez más interrelacionado ${ }^{4}$. Entre las causas de la movilización indígena podemos considerar diferentes factores (Menéndez, 2002; Gómez, 2003):

\footnotetext{
${ }^{2}$ El análisis del pluralismo religioso latinoamericano con especial incidencia en el pentecostalismo como agente del reencantamiento y visibilidad de lo religioso en la esfera pública puede verse en los estudios de Pilar Sanchiz Ochoa (1998 y 1999) y Manuela Cantón (1998).

${ }^{3}$ Gil Tébar(1999) ha expuesto las claves del desarrollo de la Pastoral Indígena y la Teología India en el catolicismo desde las caducas formas indigenistas hacia las nuevas formas de autogestión del indianismo y consolidación de una iglesia autóctona, enraizada en los diferentes grupos indígenas, como un proceso de inculturación (contrario a la aculturación anterior) y reivindicación.

4 Aunque la génesis de los principales movimientos indígenas hondureños se inicia en los años
setenta no será hasta finales de los ochenta y noventa cuando se produce la eclosión de
organizaciones y confederaciones. Así podemos citar, entre otras, federaciones de indios pech
(FETRIP), tawahkas (FITH), lencas (ONIHL), miskitos (MASTA), garífunas (OFRANEH), xicaques de 
- El fin de la "guerra fría" y la consolidación de un proceso general en torno a los derechos humanos. Pese a que Honduras fue base de movimientos contrainsurgentes en el área centroamericana y ello impidió la aparición de movimientos internos revolucionarios, en cambio, favoreció un cierto avance de organizaciones de carácter cultural y étnico.

- Cierto avance de la democratización y regeneración de las organizaciones políticas internacionales en torno a criterios como la "sostenibilidad", "justicia", "derechos Indígenas", "ecología" o el "acuerdo y diálogo".

- El impacto y desarrollo de una pluralidad de organizaciones e instituciones que ponen en marcha amplios programas de cooperación y desarrollo en la zona.

- Una nueva sensibilidad internacional hacia temáticas medioambientales, bioéticas y étnicas (Mackay, 2001, 2002, 2006; Anaya, 2005)

En las páginas que siguen analizaremos el contexto, desarrollo, características y significados de un movimiento étnico-religioso surgido recientemente en el área chortí de Copán en Honduras, aunque con conexiones en Guatemala: Ia Iglesia del Siglo Nuevo o Nuevo Katum.

\section{Contexto histórico y cultural}

Los sucesivos intentos de clasificación de los grupos indígenas americanos no siempre han reconocido e identificado con claridad y rigor la pluralidad de grupos étnicos de Honduras. Las tipologías y controversias entre Steward, Chapman, Kirchoff, Adams, Fox, Baudez, entre otros, muestran la dificultad para trazar las fronteras culturales en una zona de interacción entre grupos mesoamericanos, caribeños y no mesoamericanos. Pero al mismo tiempo desvelan los presupuestos antropológicos de los análisis basados en diferentes perspectivas culturalistas, ecológicas, económicas, lingüísticas, arqueológicas o históricas. Linda Newson (1998a, 1998b) admite la dificultad a la hora de trazar unos límites precisos, de ahí que cobre especial relevancia en su análisis la distinción entre formas políticas de grupos tribales y cacicazgos, y no entre áreas y grupos culturales mesoamericanos.

Yoro (FETRIXY), chortís (CONICH), etc. Todas ellas se agrupan en la Confederación de Pueblos Autóctonos de Honduras (CONPAH) creada en 1992. 
Precisamente la supervivencia posterior de los grupos indígenas tendrá una correlación entre la naturaleza y distribución de los sistemas sociopolíticos en la época de la conquista (tribus o cacicazgos), el tipo de institución colonial ejercida para su control: encomienda, esclavitud, misiones religiosas y la naturaleza y cantidad de los recursos. Los Chortís de Honduras constituyen un grupo étnico poco conocido por los investigadores sociales, aunque sí lo han sido sus parientes de Guatemala, véanse al respecto las obras de Girard (1949); Wisdom (1961); Mosquera (1984); Flores (1995); Hassemann et al. (1996) y Martínez (1997). Junto a los Pech, Tolupanes o Xicaques, Tawahkas, Misquitos, Lencas, Garífunas y Creoles forman parte de la realidad multicultural hondureña. Una selección de obras de referencia sobre los diferentes grupos indígenas de Honduras puede ser la que ofrecen: J. Tojeira (1982); Cruz Sandoval (1984); Anne Chapman (1985); De Andrade Coelho (1986); Lanza et al. (1986); Lázaro Flores y Griffin, W. (1991); Linda Newson (1992); Ramón Rivas (1993) y Lara Pinto (1997).

Sin embargo, esta realidad pluriétnica sigue siendo desconocida o ignorada por el resto del país, que construye un "imaginario nacional mestizo" donde reina la armonía étnica y oculta los conflictos. Para Brenda Mendoza, el carácter multirracial y multicultural resultado de la conquista y de los flujos migratorios posteriores de caribes-africanos y árabe-palestinos permanece ignorado en los discursos políticos: "Y es así como la mayoría de hondureños desde 1930 hasta hoy configuran su identidad: pensándose habitantes de un país donde reina la armonía entre las razas, pues las dos únicas razas reconocidas, la de los españoles y la de los indígenas, se ha fusionado en una sola par conformar el mestizo" (Mendoza, 2001:259). Dicho imaginario elaboró un discurso idealista del mestizaje en las primeras décadas del siglo XX que oculta la estrategia de los grupos criollos para redefinir su protagonismo ante, por un lado, el desarrollo neocolonial bananero instaurado por los Estados Unidos, y por otro, la inmigración árabe-palestina de principios del siglo $X X$, que logran rápidamente una posición ventajosa en el nuevo orden económico. $Y$ precisamente:"no sólo su naturaleza ficticia se hace visible sino que también su función ordenadora de un sistema que está programado para limitar y legitimar el acceso a los bienes materiales y simbólicos a unos mientras se los niega a otros" (Mendoza, 2001:260). En dicho proceso se encuentran fenómenos como la exclusión de lo africano de la historia nacional o la ocultación de la proporción de 
negros y mulatos de las estadísticas. De este modo, la inclusión formal y abstracta de los grupos indígenas en la identidad nacional oculta su negación y discriminación real. En esta misma dirección se encuentra lo que autores como Euraque (1996) y Mortensen (2001) han denominado la mistificación de lo indígena en símbolos nacionales míticos o la "mayanización" de todos los grupos étnicos del país y de la historia patria ${ }^{5}$.

Distribuidos en el área noroccidental de Honduras en los departamentos de Copán y Ocotepeque, los chortís forman parte de los grupos de influencia maya más meridionales. Y guardan relación lingüística y cultural con los chontales y choles más septentrionales. En la actualidad su población está formada por unas diez mil personas que conviven con la población ladina mayoritaria en la zona, aunque los indios tienden a concentrarse en la zona montañosa de Copán en las aldeas y caseríos de: San Antonio Tapesco, Choncó, Carrizalón, Rincón del Buey, Boca del Monte, Corralito, Carrizalito, El Níspero, Chilar, El Tigre, La Laguna, Estanzuela, Barvascadero, San Rafael y Monte de los Negros. Dichas comunidades están asentadas en las faldas y valles de la Cordillera del Merendón con niveles de altura entre los mil y dos mil metros sobre el nivel del mar y a menos de veinte kilómetros de la actual frontera de Guatemala. La estructura familiar es la base de todas las relaciones sociales y económicas. Marca los ámbitos de sociabilidad y de cooperación en los aspectos agropecuarios, festivos y religiosos. El grupo familiar básico es el nuclear aunque también existen otras formas múltiples formadas por unidades domésticas emparentadas que viven y trabajan juntos o en vecindad.

El patrón de asentamiento de estas comunidades es de tipo semidisperso en tierras comunales aunque también existen pequeñas parcelas de propiedad individual, siendo la actividad económica fundamental la agricultura de subsistencia (maíz y frijoles) complementaria con el trabajo estacional asalariado en plantaciones de café o tabaco cercanas y a las reducidas ventas de artesanías en el centro turístico cercano de Copán Ruinas. En todo caso, su posición dependiente y subalterna en relación a la economía local y nacional, les lleva a una permanente reivindicación de sus tierras tradicionales, que pese a estar formalmente reconocidas

\footnotetext{
${ }^{5}$ La mayoría de los símbolos identitarios hondureños fueron establecidos durante la dictadura militar de Tiburcio Carias Andino que se desarrolló entre 1933 y 1948. Otras referencias sobre el tema de la construcción de la identidad nacional son: Marvin Barahona (1991); J.A. Cruz Oliva, (1998); Carmen Murillo Chaverri (1996).
} 
desde hace más de una década, las usurpaciones y conflictos son recurrentes. Ello explica que todavía se mantengan situaciones de indios apatronados (sin propiedad de las tierras y con la obligación "clientelar" de tipo precapitalista de trabajar con días de mano en los cortes de café o en el cuidado del ganado de sus patronos) en las comunidades asentadas en las zonas montañosas más altas. A diferencia de los chortís de Guatemala, con quienes guardan continuos contactos debido a la proximidad y las relaciones familiares, los hondureños han perdido signos diacríticos étnicos como la lengua o los vestidos tradicionales, si bien en la actualidad parecen existir intentos de revitalización.

Las relaciones intraétnicas con los grupos sociales de la misma etnia en Guatemala contribuyen con bastante probabilidad a que desarrollen un sentimiento de pertenencia étnica y de diferenciación. Y ello porque las relaciones de subordinación y racismo que los vincula a los mestizos de la zona no conduce a que se sientan integrados sino a todo lo contrario, a su exclusión. Su autoidentificación y la identificación de los otros, son procesos de afirmación y negación, de negociación constante en la reconstrucción histórica y en la memoria colectiva. Por eso, aunque la lengua chortí se encuentra casi extinguida, la percepción de pertenencia grupal y las celebraciones religiosas y festivas permiten elaborar una conciencia identitaria propia.

Pese a ello, Ramón Rivas (1993: 212) en su completo y clásico estudio, niega un carácter étnico diferencial a los grupos chortís de Honduras debido a los procesos de aculturación crecientes, por ello opta por denominarlos "campesinos de tradición chortí". Además no incluye a los grupos de Ocotepeque por el marcado proceso de ladinización a su juicio existente y ello pese a que éstos últimos se autoidentifican como chortís y fueron los primeros activistas de la etnia ${ }^{6}$.

\footnotetext{
${ }^{6}$ A este respecto, resulta esclarecedora la reflexión crítica de Eduardo Menéndez (2002: 95-171), sobre la construcción ideológica de las categorías antropológicas. Del énfasis en los aspectos económico-políticos que convirtieron la etnicidad en campesinado se ha pasado a la reducción de sus aspectos económico y a la resignificación de sus derechos culturales e identitarios. De tal manera que sus acciones y demandas, incluidas las luchas político-económicas, se articulan a través de reivindicaciones étnicas y culturales. Precisamente, la apreciación de la naturaleza campesina de los indígenas se consolidó en un contexto económico y político dominado por dos grandes paradigmas teóricos: la modernización y las políticas estatales asimilacionistas. Por el contrario, el énfasis étnico se debe a factores como: el debilitamiento de los Estados, la crisis de las reformas agrarias, las nuevas políticas impuestas por el FMI, el auge de medidas de desarrollo sostenible, una nueva percepción de los problemas ecológicos, el desarrollo de las organizaciones políticas indígenas y los cambios en las concepciones sociológicas y antropológicas (Monreal, 2003).
} 
La apropiación de la cultura maya por parte del Estado hondureño ha sido uno de los factores de negación de la cultura chortí y de usurpación de su historia específica. Como comenta Mortensen (2001), la arqueología y luego el turismo han constituido la estrategia de construcción y articulación de la historia nacional. Ello explica que "el papel de Copán sea continua y explícitamente enfatizado por varios medios", o que "Copán no sólo ha emergido como producto de la arqueología, el turismo y las producciones del Estado sobre patrimonio e historia, sino que ha sido elaborada en el caldero histórico del imperialismo transnacional" (Mortensen, 2001: 126-129). La estela de Morley, Stephens, Catherwood y Stone continúa pues en la actualidad. Frente a esta lógica ideológica, los verdaderos mayas y el resto de grupos indios aparecen ocultos, subordinados y esquilmados. Todo ello explica que las ruinas, como símbolo nacional, fueran ocupadas el 12 de Octubre de 1998 por casi dos mil indios chortís en deshonor al Día de la Raza y la Conquista, en reclamación de tierras y derechos y solicitando investigación sobre la muerte de algunos de sus líderes que quedaron impunes. La violencia simbólica del acto sacudió las conciencias de los grupos de interés nacionales y además el bloqueo del acceso al parque arqueológico supuso un coste económico elevado.

El elemento central de la religiosidad chortí tradicional lo constituye el tzikin. Los tzikines son rituales de ofrenda y comunicación con los muertos que se celebran en el mes de noviembre. También suelen celebrarse tras la muerte de algún familiar o vecino. Pueden tener un carácter familiar o comunal ${ }^{7}$.

La observación participante y el trabajo de campo, a lo largo de varios años pero con diferente y desigual intensidad, han podido identificar la presencia en el campo religioso chortí de Copán de cuatro agentes que compiten por el capital simbólico comunitario: el culto maya ancestral teñido de sincretismo católico, el

\footnotetext{
${ }^{7}$ En las viviendas se colocan altares familiares decorados encima de una mesa o tapesco con flores, bebidas, comidas (maíz, ayotes, puros, chepes, tamales), regalos, velas, copal, cruces y hojas de pino como ofrenda a los muertos. Estos altares son bendecidos por los chamanes o chucureros que durante toda la noche, pero en un ambiente de alegría, realizan plegarias y rezos. Al concluir las oraciones, tras una agitada noche y ya de madrugada, se reparten y consumen entre los asistentes las comidas y bebidas. Las funciones sociales de cohesión, comensalismo, participación activa, solidaridad, esperanza y comunicación han sido destacadas por autores como Flores (1995: 77-79) y Martínez (1997: 53-56).

Otra ceremonia de la religiosidad tradicional chortí es el padrineo del agua. Cuando los cultivos necesitan lluvias o la comunidad padece tensiones, el chamán o padrino se dirige en procesión con la comunidad a cenotes o lugares sagrados (especialmente pozas, manantiales o cimas de montañas). Allí celebra un breve ritual de plegarias y ofrendas hasta acabar con el sacrificio de algún pollo o jolote (pavo). Los huesos de estos animales previamente hervidos y ofrendados se colocan en la orilla de las pozas y luego son arrojadas al agua o enterradas en su orilla.
} 
catolicismo, los cultos protestantes y la Santa Misión o iglesia milenarista del Siglo Nuevo. Dicha competencia, a nivel estructural, se refleja en los propios agentes del mercado simbólico indígena chortí. Así, por ejemplo, en la aldea de Carrizalón ${ }^{8}$ (con menos de setecientos habitantes), y dependiendo de los intereses, problemas, inquietudes, ofrendas y expectativas, un chortí puede dirigirse a Don Leonardo o a María Jesús, rezadores y celebradores de la costumbre; a Modesto Oaxaca, chucurero de la tradición maya chortí, que afirma que "si se reza en chortí se tiene mejor resultado porque los dioses escuchan mejor" ; o a Guillermo García, otro chucurero tradicional pero luego fundador del Nuevo Siglo. $Y$ aunque las comunidades son muy pequeñas y el sentido comunitario es muy fuerte, la competencia y conflictos están siempre latentes.

\section{De auxiliares estatales a líderes campesinos. De campesinos a} indígenas.

A partir de los años setenta en las tierras altas del Departamento de Copán, más próximas a Guatemala, comenzó a gestarse un movimiento social de lucha por la tierra y afirmación identitaria frente a las injusticias y la desigualdad de su exclusión social. Las reformas agrarias que se implementaron sólo dieron respuesta formal a las reivindicaciones concretas, dado que las formas de explotación comunal por parte de latifundistas, hacenderos y rentistas se mantienen, con matices, hasta la actualidad. Al hilo de estos procesos reivindicativos que transformaron, en apenas treinta años, los supuestos ideológicos de los agentes sociales, las categorías ${ }^{9}$ sociales analíticas fueron también permutando su sentido y referencia: de los auxiliares estatales en las comunidades de los años sesenta se pasó a los líderes campesinos de los setenta y ochenta, hasta llegar a los actuales líderes indígenas organizados en el Consejo Nacional Indígena Chortí de Honduras en 1994 o

\footnotetext{
${ }^{8}$ Nuestros últimos datos referidos al año 2005 atestiguan la presencia en Carrizalón de una nueva misión evangélica. Dicho fenómeno constata el crecimiento de la evangelización protestante en todas las áreas geográficas y sectores sociales hondureños. Pero, al mismo tiempo, desvela la interrelación entre las transformaciones socio-políticas del área de Copán y los renacimientos religiosos.

${ }^{9}$ Sobre el uso y desuso en la construcción de los conceptos antropológicos, los olvidos, contaminaciones e ideologías de la disciplina, véase: Eduardo Menéndez (2002).
} 
CONICHH (amparados por la Confederación Nacional de Pueblos Autóctonos de Honduras o CONPAH y algunos profesores y estudiantes de la UNAH y la UPN).

Estos movimientos socio-políticos de base étnica, articulados en la lucha por la tierra, el cambio en la organización social y en la afirmación identitaria, guardan una estrecha relación con la diversidad de procesos religiosos de la región. En el fondo de estos movimientos se encuentra la revitalización de componentes culturales ancestrales mayas que consideran a las tierras, aguas y sus productos como elementos divinos. Esa memoria histórica se articulaba en ceremonias tradicionales sincréticas como los tzikines, el padrineo del agua y el calendario festivo. Pero sus instituciones y rituales aparecían subordinados o sustituidos respecto a las a las celebraciones de las instituciones religiosas y sociales hegemónicas estatales. No obstante, la influencia católica siempre había sido débil en la zona, concentrada en la parroquia de Copán Ruinas y en las escasas ermitas de lo cerros de la zona, y aunque la mayoría se consideraban y consideran católicos de la costumbre, el ejercicio real de la evangelización y control quedaba relegado a delegados y celebradores de la palabra indígenas (dada la escasez de sacerdotes católicos, la lejanía de las iglesias y las deficientes vías de comunicación con caminos de herradura y la inexistencia de cofradías o hermandades), que en muchos casos reapropiaban y reelaboraban los elementos cristianos con los elementos mayas: cruces, altares, plegarias, bautizos, ceremonias festivas, bendición de granos, velorios de agradecimiento o el propio santoral más importante: San José, San Marcos, San Sebastián, San Marcos, Santiago, San Andrés, San Silvestre, los Ángeles y la Virgen María. Los ladinos acusaban a los indígenas chortís de esta redefinición de los rituales y las funciones de los sacerdotes. La facilidad con que los indios adaptaban y mimetizaban las funciones, cargos y ritos cristianos, ha sido siempre objeto de conflictos. Los sacerdotes (chamanes 0 chucureros o padrinos chortís, varones ancianos respetados y ejemplares) sustituyen a los sacerdotes católicos como celebradores de la palabra. Y sus funciones y rituales ancestrales se complementan con los católicos (bautizos, oraciones, casamientos). Sin embargo, los sacerdotes católicos no pueden sustituir como es natural a los indígenas en ceremonias tradicionales como tzikines o el padrineo del agua (Martínez, 1997:33). 
En las zonas más bajas, próximas a los valles y llanuras, del Departamento de Copán, donde los procesos de ladinización acompañan la implantación de nuevas formas económicas capitalistas en forma de cooperativas, empresas transnacionales dedicadas al cultivo de café, tabaco o caña, y empresas ganaderas, comenzaron a extenderse desde los años sesenta iglesias evangélicas y pentecostales de procedencia norteamericana aunque con base en la zona bananera de la costa norte caribe. De este modo el proselitismo religioso acompañado por cambios en los modelos de racionalidad económica y ética más cercanos al individualismo y al capitalismo pero que incluye mejoras evidentes en los campos educativos, sanitarios y de viviendas. Si bien es verdad que estos procesos no pueden interpretarse de manera mecanicista dado que se excluiría el papel de los actores sociales en la reapropiación de los mensajes religiosos (Cantón, 1999). De hecho, estas mismas condiciones de aparente modernización económica, que en los indígenas chortís de la zona implica siempre una posición subalterna y dependiente, no impiden que en los últimos años el movimiento del Nuevo Siglo comience a extenderse en las trabajadores temporeros o sedentarios chortís de la zona.

En este contexto el activismo indígena ha devuelto protagonismo a los descendientes de los autores de las ruinas de Copán. El movimiento Nuevo Siglo constituye una manifestación de los movimientos sociales emprendidos en la zona y a la revitalización étnica y política se unió la religiosa. De este modo, la religión puede formar parte del interés de los indios por organizar cierta arquitectura simbólica de seguridad para su existencia. Establece energías y estrategias comunitarias de acción simbólicas eficaces para interpretar las necesidades vitales inmediatas. Y frente a las religiones cristianas históricas, incapaces en su ambición universalista de asumir las condiciones de pobreza y contextos particulares indígenas (o a lo sumo sólo de forma retórica), los nuevos movimientos religiosos milenaristas asumen de forma heroica la tarea incómoda de enfrentarse a la sociedad del riesgo, las desigualdades e injusticias y la anomia social y moral que distorsiona y sacude el edificio cultural de las comunidades indígenas en los tiempos confusos de la globalización.

Como analizaba Marzal (1985: 175), las ciencias sociales no cuentan todavía con una teoría general que pueda explicar adecuadamente la complejidad y diversidad de los fenómenos sincréticos. La necesidad de estudios particulares 
sobre los procesos de aculturación o los nuevos movimientos religiosos posibilita que la antropología, por su metodología y tradición, sea una disciplina adaptada a esos cometidos.

El campo religioso chortí responde a los conflictos y procesos de etnogénesis de las últimas décadas en Honduras. Tanto la revitalización de las ceremonias ancestrales mayas de los tzikines o el padrineo del agua, como la aparición de la iglesia mesiánica y milenarista del Siglo Nuevo forman parte de un esfuerzo colectivo simbólico por adecuar y sostener las relaciones sociales identitarias y restablecer el equilibrio y solidaridad del grupo chortí en momentos de cambio social y ladinización creciente. Ambos posibilitan rituales donde la communitas refuerza los sentimientos de solidaridad y cohesión social. Pero al mismo tiempo, desvelan las tensiones y conflictos intraétnicos e interétnicos de los procesos históricos y sociales en los que se enmarcan. En este sentido, los movimientos milenaristas y nativistas son también en parte expresiones del fracaso de las estrategias culturales tradicionales para resolver esos nuevos conflictos.

El milenarismo de tipo mesiánico con sus rasgos de legitimación y reivindicación de un pueblo elegido perseguido y discriminado históricamente como los chortís de Honduras, el rechazo a la contaminación de influencias extrañas, las profecías de destrucción y castigo, la esperanza de un renacimiento material y espiritual comunitario o la aparición de líderes carismáticos que movilizan y cohesionan a las comunidades indias frente a los representantes de las instituciones religiosas o estatales, conjuga elementos revivalistas y nativistas ${ }^{10}$.

El milenarismo surge en el área chortí debido a la influencia de circunstancias específicas locales, internacionales e históricas como los movimientos indígenas y los efectos locales de la globalización a través del arqueoturismo y nuevas formas del capitalismo.Y como respuesta a las necesidades sociales y simbólicas étnicas en paralelo a la génesis de movimientos socio-políticos identitarios que dieron lugar a la aparición del $\mathrm{CONICHH}$ y al proyecto de regeneración nacional desde el reconocimiento de la realidad multiétnica de Honduras, a partir del reconocimiento

\footnotetext{
${ }^{10}$ Wallace (1972) resumía sintéticamente las fases de estos tipos de movimientos sociales: partiendo de una situación cultural estable, se suceden períodos de tensión individual y grupal debido a factores internos y externos al propio grupo y que dan lugar a períodos de distorsión cultural. Ello posibilita la aparición y formulación profética de un código utópico al que le siguen las fases de comunicación, organización y adaptación del movimiento mesiánico. Wallace sostiene que estos tipos de movimientos de transformación cultural suelen ser cíclicos y que, por tanto, suelen llegar a fases de rutinización y vuelta a la estabilidad cultural.
} 
en 1994 del Estado hondureño del convenio $\mathrm{n}^{\circ} 169$ de la OIT sobre Pueblos Indígenas (inicialmente canalizados en la lucha por la tenencia de la tierras y la reivindicación de derechos económicos, sociales y políticos).

Los elementos centrales del movimiento socio-religioso proceden de los mensajes proféticos de su líder, basados en componentes culturales ancestrales mayas y en las costumbres tradicionales del proceso de aculturación tras la conquista. La aparición concreta en los años noventa se puede también explicar por la convergencia de los factores anteriores, el descontento por las condiciones de vida, la autoconciencia de la necesidad de lucha y transformación social que generaron los movimientos indios en toda Latinoamérica y la cristalización concreta de elementos psicológicos, sociales y culturales en un líder mesiánico como Guillermo García.

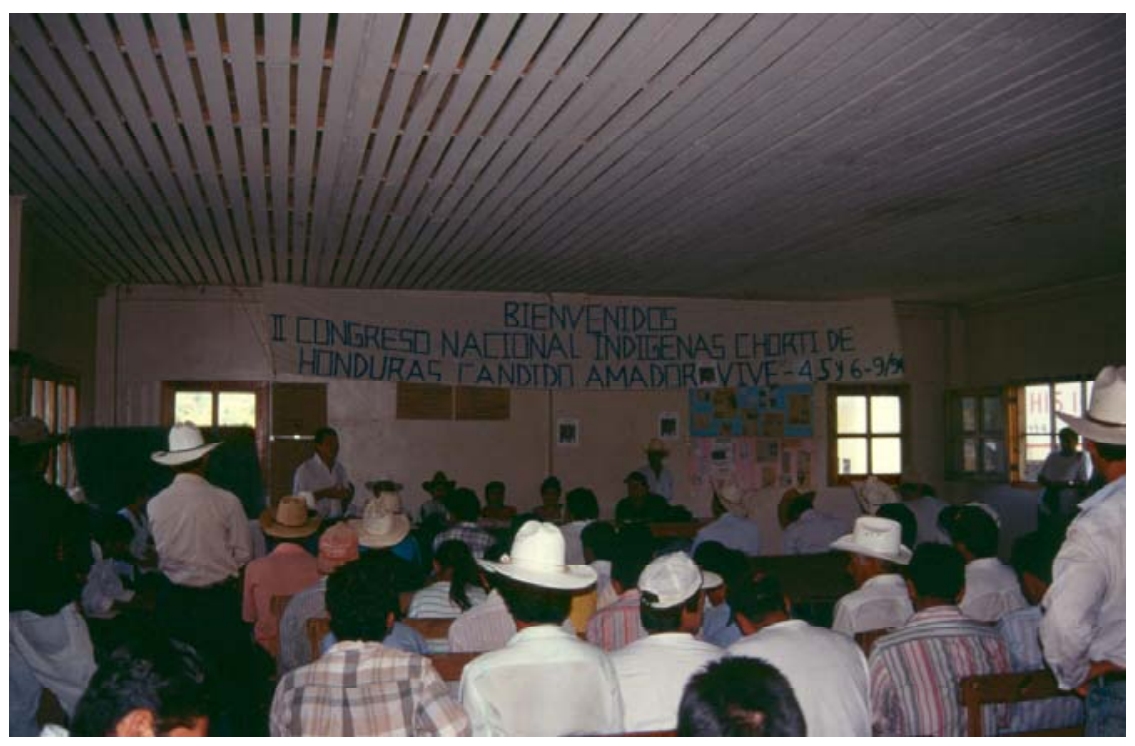

IMAGEN 1. II Congreso Nacional Indígena Chortí de 1998. Rincón del Buey. (Foto de los autores).

\section{Orígenes, estructura y proclamas de la iglesia Siglo Nuevo.}

En la comunidad de San Antonio Tapesco, a pocos kilómetros de la frontera con Guatemala, tiene su centro espiritual y ceremonial la Iglesia del Nuevo Siglo. Se trata de una iglesia nativista que intenta recuperar los elementos tradicionales de la religión maya chortí como la veneración de los fenómenos naturales o el culto a los muertos. Al nativismo se le unen también elementos milenaristas como el fin de los 
tiempos, el anuncio de un nuevo ciclo temporal y las promesas proféticas. La reivindicación de la cultura maya se vincula con el interés por establecer alternativas de esperanza colectiva para la etnia, que pasan por el renacimiento personal y comunitario. La salvación pasa por la destrucción del "siglo viejo" y la restauración de un mundo nuevo y mejor para los chortís. Esta concepción escatológica y cíclica de la historia hunde sus raíces en la tradición maya. Pero además de los elementos prehispánicos, el nuevo movimiento religioso se apropia y redefine elementos del cristianismo como el santoral, la figura de los ángeles o la denominación de Santa Misión o casa parroquial al centro ceremonial. Otros elementos, en cambio, aunque existieron en la cosmología maya, como la cruz (representando el centro del mundo y los cuatro puntos cardinales) o la figura del Mesías, tienen su origen en formas sincréticas. Su fundador es un chucurero o chamán indígena: Guillermo García, casado, analfabeto y de 55 años de edad. Nacido en la aldea próxima del Guayabo en el departamento de Chiquimula en Guatemala, aunque hay que tener en cuenta que las relaciones transfronterizas entre los chortís de ambos lados de la frontera son habituales.

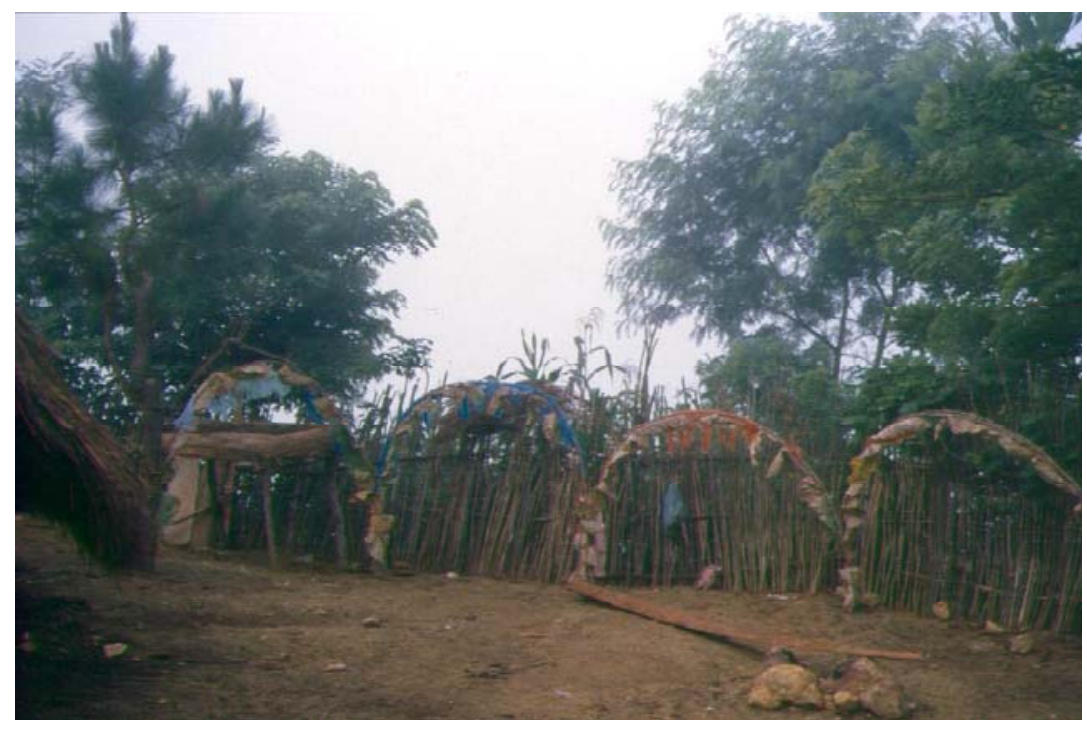

IMAGEN 2. Patio del centro ceremonial de la Iglesia Nuevo Siglo. San Antonio Tapesco (Foto de los autores). 


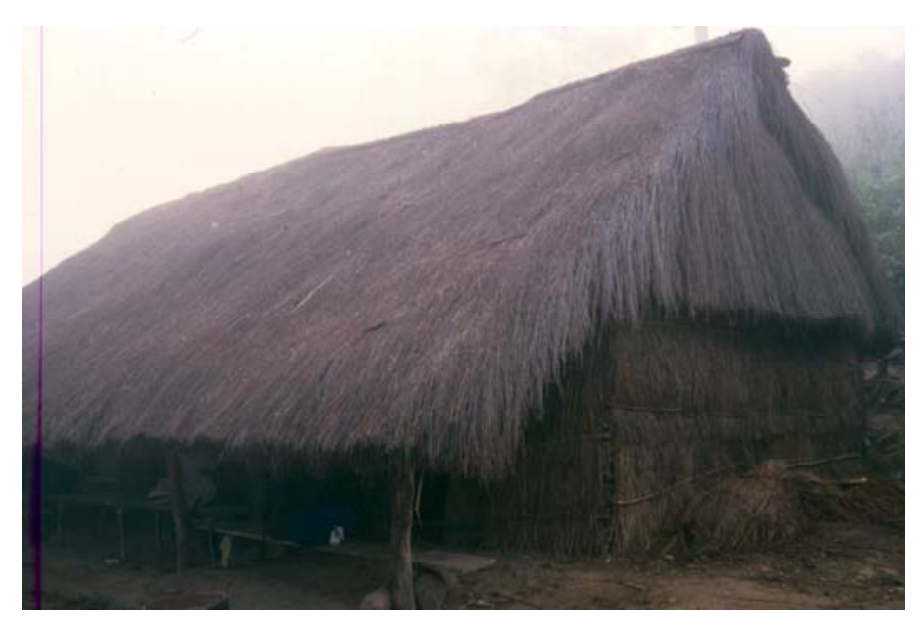

IMAGEN 3. Centro ceremonial de la Misión Santa del Nuevo Siglo. San Antonio Tapesco. (Foto de los autores).

En el área chortí de Guatemala surge el movimiento a finales de los setenta pero no se instaura y desarrolla en Honduras hasta principios de los noventa. Guillermo se proclama el único Mesías, tras recibir los "dones para representar al Siglo Nuevo por Dios Padre" y como tal dice poseer facultades para interpretar los mensajes de destrucción del siglo anterior y profetizar el nuevo milenio. Su ungimiento y consagración le permite curar enfermedades, ahuyentar malos espíritus, aconsejar en disputas familiares o comunales y ser respetado por todos los integrantes de la comunidad. Él es el enlace único y verdadero entre el pueblo y Dios. Su "bendición y elección" procede del año de 1978 cuando, según cuenta, "murió durante varias horas y su alma fue conducida ante el Padre que le dio los poderes y le devolvió a la vida" (Flores, 1996; Martínez, 1997). A primeros de los noventa, con ayuda de algunos vecinos, levantó el centro ceremonial en lo alto de una colina en San Antonio Tapesco. Al mismo tiempo reside y preside alternativamente otra Misión en su aldea de Guatemala. La Misión Santa cuenta con dos espacios básicos: en primer lugar, un amplio recinto cerrado con palmas, varas y hojas y en el centro una gran cruz decorada y llena de ofrendas; y en segundo lugar, una casa de oración donde se encuentra el altar sobre un tapesco decorado de hojas, ofrendas, velas, incensarios de copal, cruces, santos y vírgenes. En el interior de la sala hay otro tapesco auxiliar, un conjunto de carteles con proclamas y profecías, y ofrendas como machetes, armas y rifles de madera que se utilizan en las ceremonias por parte de los guardianes del centro sagrado para proteger al 


\section{Mesías y a la comunidad de la influencia de los malos espíritus. Sus mensajes y profecías son confusos, a veces contradictorios, utilizando un lenguaje metafórico y aforístico donde se mezclan los términos y los significados de las palabras.}

"Habló el Padre. Examinó a Guillermo García, que se está anotando, dijo el Siglo, que lo están imaginando. Entonces dijo el Siglo anterior que no son sueños, dijo el Siglo anterior a las dos de la mañana, cuando cantó el primer pollo. Estábamos con él. Estábamos los dos siglos. Les estaban dando a saber que de muy vivos los quieren enredar en pláticas. No sean papos ustedes cuando va a llegar a parar toda la generación hay que hacer una obligación, de hacer una alegría, de una música de banda de merecimiento para el Nuevo Siglo.

Atención. el 91, el 92 y el 93, entonces desde el 91 estaba prendido una electricidad. Estaba hablando con el Padre a todas las personas para que se conecten y entonces apaciguar estas calamidades, entonces el primero de agosto volvió a avisar el Padre. Dice que el mundo estaba prendido. Entonces las personas que allí están andando tienen esa persona que ha enviado el Padre. Entonces el Padre mandó levantar un representante.

Él tiene desde que murió, quince años, entonces después desde los quince años que él murió se está hablando a toda la generación. Entonces hoy el tiene su representante que está dando saber. Entonces el representante está hablando de todas las calamidades que están pasando porque él murió el 25 de octubre de 1978.

El "contumento" [documento] del Siglo. Atención. El "contumento" del siglo y el "contumento" del siglo anterior, que hoy para allá no quiero guerras, que yo dejo mi palabra, que yo soy comandante y soy comandante para que dejéis las armas, que sólo mis coronas lo vence. Yo descubro Centroamérica, nuestros hijos, me muero también como un "presentante", yo lo estoy diciendo porque no lo creyeron, el que vino a legitimar.

Atención! Habla el siglo anterior y el siglo Nuevo, veinte años de lo que hemos conocido y cuando murió son catorce años. Por medio de la comunidad Guillermo García fue reconocido que de ninguna autoridad fue amenazado y en la aldea del Guayabo, municipio de Camotán, departamento de Chiquimula, primero empezaron cuidando a los hermanos. Entonces después habla el Siglo. Cuando despertó y comprueban sus familias. Particularmente dijeron que era un engañador. $Y$ no era engaño, sino que era la purísima verdad porque así le hablaban del siglo anterior y por una casa parroquial" (Flores, 1996:47-49)

IMAGEN 4. Milenaristas de madera. (Foto de los

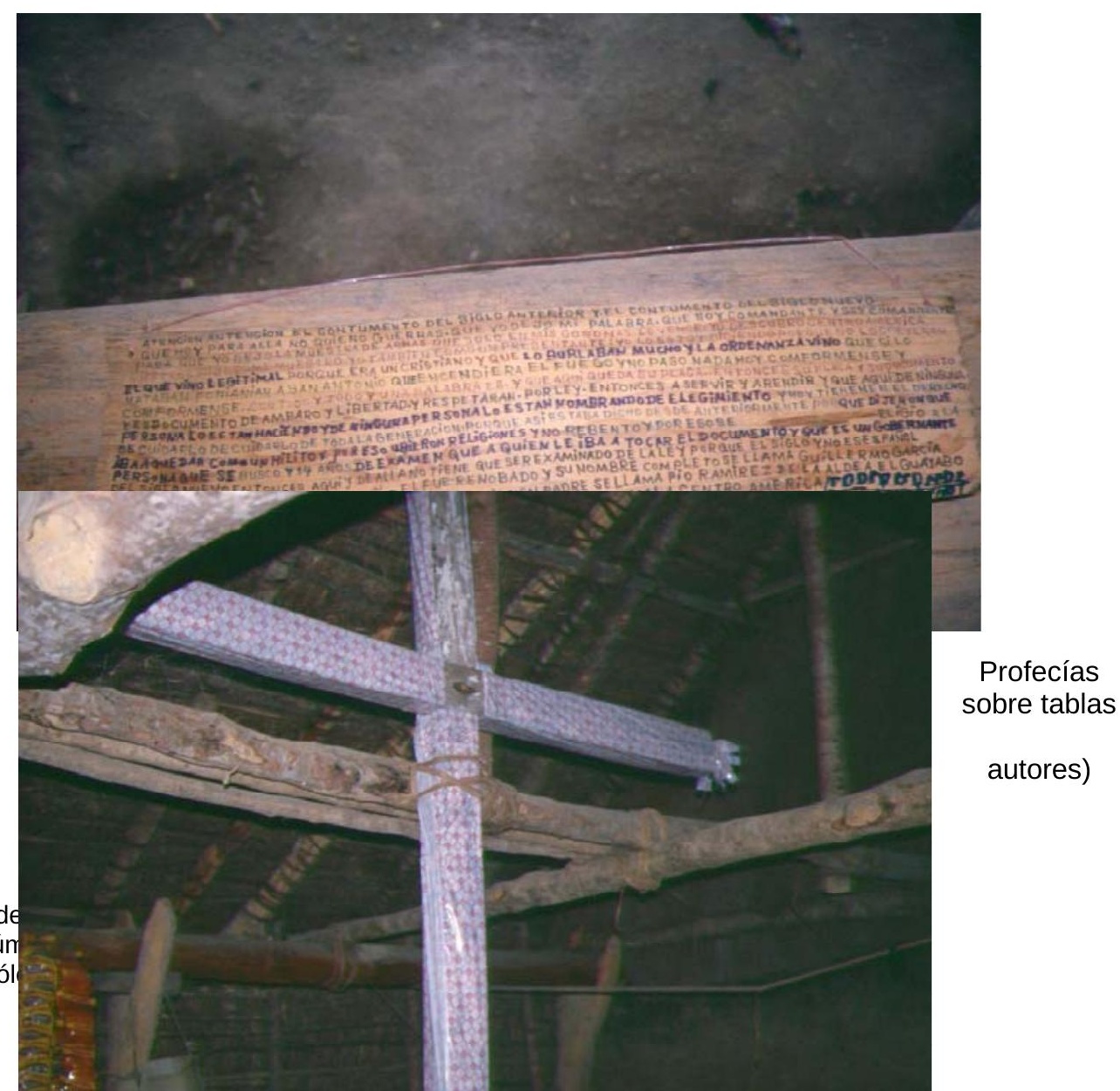


IMAGEN 5. Cruz blanca en el interior de la Misión Santa.

(Foto de los autores)

A su comprensión tampoco ayudan los documentos y carteles que proclaman sus mandatos y profecías, que redactan algunos seguidores escribanos, dado que el Mesías no sabe leer ni escribir. Dichos mensajes son fundamentalmente la defensa de los valores culturales chortís, la esperanza de una nueva generación, el restablecimiento de la solidaridad y reciprocidad comunal, el peligro de contaminación exterior, los castigos y amenazas de incumplimiento de sus mandatos, la invocación a sus poderes para "defender el grano de oro" (maíz), "la sabanita de oro" (tortilla), etc. He aquí otra muestra que reproduce algunas de las ilustraciones y su credo:

"Che, organizar para el nuevo siglo. Che, convertir. Che, coronar. Che, corporar. Che, gobernar. Che levantar la Misión Santa. Che, defender el granito de oro. Che levantar los ángeles. Che, levantar las montañas. Che, defender la sabanita de oro. Che, defender la pita de oro. Che, defender la cruz blanca de Cristo. Che, hablar del siglo anterior porque habrán muchas calamidades. Che, terminar con la fe anterior, por eso hay pobreza.

Respetar a sus padres, respetar a sus esposos aunque no sea casado, pero respetarlo. El que cuida a su esposa cuida su vista, su espíritu y su corazón.

El representante del siglo no puede ser español, pues las religiones son venidas de otras naciones. No son nacidas en Centroamérica y por eso nos vienen votando.

Tiene que estar el nuevo siglo, tiene que estar el cambio, porque si no hay cambio no vamos a acabar y en este cambio van a desaparecer las religiones porque sino nos vamos a morir de hambre" (Flores, 1996:48; Mena, 1998. Diario de campo).

La organización del movimiento se estructura con los Caminantes, personas elegidas, respetadas y que cumplen funciones especiales en el funcionamiento de la iglesia: organizar las ceremonias, preparar y auxiliar a los enfermos, transmitir 
informaciones con discreción, etc. Uno de esos Caminantes, proclamado por el Mesías, es paradójicamente el antropólogo Lázaro Flores, debido a sus esfuerzos por el pueblo chortí. Le siguen los Miembros Parroquiales que preparan los altares y proveen de ofrendas y fondos a la Iglesia. Además existen Coordinadores que se encargan de las actividades de intermediación de la Iglesia con cada una de las comunidades del área. Por último está el cuerpo de Guardianes, que protegen con armas ficticias el santuario y al Mesías en las ceremonias. Junto a los tzikines existen celebraciones periódicas en la Santa Misión donde se "procesiona" y desfila por el interior del santuario, se curan enfermos, se escucha el discurso del profeta y se participa alegremente en una fiesta de música y baile con guitarras, violines y chirimías. El baile lo inician los portadores de las armas de madera y machetes, mientras las mujeres preparan comidas con atol, tamales y frescos de chicha. La fiesta se prolonga hasta bien entrada la madrugada, por esta razón se encienden velas toda la noche.

\section{Contrapunto}

Asistimos en este final de siglo a una revitalización de los movimientos sociales de base étnica en todo el mundo. En el caso de América Latina las últimas décadas han contemplado la extensión y profundización de organizaciones políticas que se autodenominan indias o indígenas. Esta eclosión de movimientos etnopolíticos no es ajena a la reestructuración geopolítica mundial tras el derrumbe de los sistemas comunistas y a una nueva estrategia de reactivación del capitalismo en forma de globalización.

Las movilizaciones étnicas representan y articulan amplios sectores de las poblaciones latinoamericanas que se distinguen conscientemente del resto, aunque en sí mismas reflejan toda una gama de contrastes y diferencias internas. Ante este contexto de modificación del espacio social, político y simbólico que ha posibilitado la eclosión de los movimientos indios y sobre todo por la dimensión política de su movilización, las sociedades dominantes y hegemónicas han reaccionado desde la violencia hasta el silencio e incomprensión. En la mayoría de los casos las políticas indigenistas estatalistas han conjugado hábiles maniobras de instrumentalización de las representaciones indígenas con la descarnada represión y violencia etnicidas. 
Un repaso histórico a las políticas indigenistas de los países americanos, pese a sus diferencias nacionales y su desigual carácter pluriétnico, muestra un objetivo latente común: la integración de los indios (Bonfil, 1981; Barre, 1983; Díaz Polanco, 1991). La constitución de los gobiernos liberales postcoloniales adoptando el modelo del Estado nacional napoleónico, impedía admitir la realidad pluriétnica de los pueblos que conformaban los límites de las antiguas fronteras coloniales. El objetivo integracionista respondía a la necesidad capitalista de consolidar y ampliar los mercados internos nacionales junto a los supuestos evolucionistas y positivistas del liberalismo criollo: se trataba de incluir a los indígenas en la vida nacional pero excluyendo su identidad cultural diferenciada. Al borrar las distinciones legales y sociales el progresismo liberal elevaba al indio a la categoría universal de ciudadano, ignorando la base indígena social los indios desaparecían como tales del proyecto nacional.

La construcción de una nación en los aspectos sociales, económicos, políticos y culturales, debía ajustarse al ideal de un Estado homogéneo, en este modelo no cabría el indio por su refractaria particularidad cultural. Es así como las minorías criollas instrumentalizaron los logros independentistas en su propio beneficio de clase dominante y modelaron el proyecto nacional diseñando una paulatina integración de indios atrasados o bárbaros al modelo civilizatorio evolucionista y positivista del estado. Hoy ya nadie puede negar que la independencia americana supuso una autodeterminación incompleta de los pueblos americanos en la medida que no trajo consigo la emancipación real de los sectores indígenas, mayoritarios en algunos países, que simplemente pasaron del dominio colonial al dominio nacional.

El movimiento indigenista integracionista, justificado en las políticas estatales para los sectores indígenas, adquiere mayor expresión a partir de los años treinta de este siglo y tiene en el Primer Congreso Indigenista Interamericano de Pátzcuaro de 1940 su definición institucional y programática: reconociendo la existencia del indio (y el fracaso de los supuestos evolucionistas liberales) se trataba de arbitrar políticas estatales especiales protectoras encaminadas a rescatar ciertos aspectos culturales no conflictivos para los grupos hegemónicos y al fomento de la incorporación del indio a la vida nacional.

Pese al reconocimiento del pluralismo étnico con ciertas dosis de relativismo cultural (en boga en los círculos antropológicos culturalistas de aquellos momentos), 
tanto las políticas indigenistas estatalistas como el indigenismo de las Iglesias católicas o las ya pujantes iglesias protestantes fueron incapaces de articular el reconocimiento real del contexto plurinacional de las sociedades latinoamericanas y mucho menos de las recientes movilizaciones etnopolíticas, de ahí que su reacción haya sido, según las condiciones históricas nacionales, o bien la pura represión directa o bien la manipulación y control hasta la configuración de un aceptable relicario cultural.

La mayoría de las organizaciones políticas de izquierda latinoamericana no han logrado tampoco aceptar ni ideológica ni prácticamente, el hecho pluriétnico nacional, las movilizaciones étnicas recientes o el renacimiento religioso. En realidad dicha incomprensión ideológica proviene de la negación o falseamiento de la realidad indígena: el indio en la tradición marxista queda subsumido en la categoría de campesino, categoría a la que por otra parte se le niega también capacidad revolucionaria autónoma.

Las ciencias sociales sólo hasta hace muy poco han ido desprendiéndose de los matices culturalistas y funcionalistas (que propiciaron las políticas indigenistas estatalistas) y han comenzado a reflexionar sobre el reto intelectual que las movilizaciones étnicas representan en la actualidad. Pero uno de los mayores obstáculos para la comprensión de la eclosión de la etnicidad ha sido intentar, de forma prematura, forjar una teoría explicativa de carácter global. Dicho intento sólo es concebible si está asociado al desarrollo de teorías generales de los sistemas económicos, sociales y simbólicos, pero dado que dicha posibilidad ha resultado bastante problemática lo más razonable, epistemológicamente hablando, es facilitar la discusión de hipótesis parciales, sujetas a campos de observación contrastables y propiciar un debate democrático sobre su alcance y validez.

Todo este repaso nos permite comprender las claves de la etnicidad chortí en Honduras. Pese a la pervivencia de los patrones culturales mayas en el área, su visibilidad externa se había mantenido difusa y deformada hasta la actualidad. Entre una situación y otra han intervenido diferentes procesos culturales, políticos e históricos. Precisamente, la escasa movilización étnica y la invisibilidad maya constituían una estrategia de resistencia a la integración. Este hecho es fundamental para comprender el movimiento étnico y religioso emprendido en los últimos años, porque explica la eficacia de los diferentes de factores de bloqueo y mistificación, 
que como hemos comentado en páginas anteriores fueron impulsados por el Estado en la construcción ideológica de una historia oficial nacional. Dichos bloqueos y alienaciones han impedido o deformado la percepción consciente de la etnicidad chortí, su historia, el significado de sus experiencias culturales o sus relaciones con otras etnias. Así, por ejemplo, a los chortís o se les niega su pasado maya o se le deforma su singularidad al construir una identidad estatal hondureña genéricamente maya, una estrategia esta última que, a la vez que inventa un pasado étnico inexistente para gran parte de los pueblos de Honduras desactiva y debilita el potencial étnico chortí. En otros casos la pérdida de la lengua propia se confunde ideológicamente con la ausencia de etnicidad chortí, o más frecuentemente, la utilización de la denominación de "campesinos" como estrategia para disolver las diferencias. No hay que confundir, por tanto, a los elementos culturales que señalan una etnicidad con los fenómenos estructurales que definen al grupo étnico respecto a otros grupos y al Estado. Unos y otros tienen relación pero son los segundos los que actúan como catalizadores de la conciencia política y social, acentuando además la previa conciencia de etnicidad -o generando ésta desde el sentimiento étnico- al intensificar el valor simbólico de algunos de estos marcadores, como por ejemplo ocurrió en el uso de banderas amarillas en las movilizaciones chortís de Octubre de $1998^{11}$.

En otras palabras, los marcadores étnicos, como pueden ser la lengua, el territorio, la religión, las instituciones, las formas de sociabilidad, las expresiones culturales, etc, tienen por una parte, una existencia real y objetiva, pero por otra, solo se convierten en ejes de la autoconciencia de la etnicidad en contextos determinados y por medio de la acción de clases y grupos sociales concretos. Contextos que tienen que ver directamente con el papel que juega el grupo étnico y su territorio en la división del trabajo dentro del Estado, y también hoy, con la importancia creciente de los ámbitos supraestatales de decisión económica y política ${ }^{12}$.

\section{Conclusiones}

\footnotetext{
${ }^{11}$ En el conflicto pacífico que generó la ocupación de las Ruinas arqueológicas de Copán por parte de más de dos mil chortís en Octubre de 1998, éstos utilizaron el amarillo del maíz como símbolo étnico en sus banderas.

${ }^{12}$ En este análisis seguimos, en parte, las aportaciones de Moreno (1991). En cuanto a los procesos de redefinición étnica en el contexto de la globalización, véase Pérez y Dietz (2003). 
La estructura y dinamicidad del movimiento del Siglo Nuevo nos invita a comprender, desde una mirada antropológica, la pluralidad, complejidad y paradojas de los nuevos movimientos socio-religiosos en este final del milenio. No en vano, éstos han sido interpretados muchas veces como síntesis ideológicas y afectivas, teóricas y prácticas, de sectores sociales desfavorecidos y que se encuentran sin campo social y simbólico donde desarrollar su identidad. Cuando el cambio social y económico ha sido rápido y sustancial, nuevos grupos sociales se sienten necesitados de una reinterpretación o redefinición de su posición social. Así, esta hipótesis (para nosotros insuficiente) considera que los chortís como otros grupos étnicos, buscarían su propia justificación transcendental en clave de salvación personal y de grupo, y lo harían con tanto mayor rigor, cuanto más excluidos estén de la distribución del capital social y religioso existente. Su búsqueda de acomodación conflictiva a un nuevo orden real les exigiría una promesa escatológica satisfactoria en este mundo y en el más allá.

La perspectiva que sigue esta investigación, lejos de secundar los planteamientos que explican estos movimientos étnico-religiosos como respuestas a la anomia social, la privación, la desorganización social o la pérdida cultural, plantea una interpretación de los fenómenos religiosos como motores de cambio y transformación, algo que es, por lo demás, mucho más cercana a la experiencia concreta y personal de los agentes sociales. La reelaboración de este movimiento de la realidad económica, social e ideológica van mucho más allá de una mera interpretación profética del mundo al dotar a los seguidores chortís de estrategias prácticas de relación eficaz con el mundo y de transformación de las relaciones tanto intra como interétnicas.

\section{Referencias bibliográficas}

Anaya, J. (2005). Los pueblos indígenas en el derecho internacional. Madrid: Trotta.

Barahona, Marvin (1991). Evolución histórica de la identidad nacional. Tegucigalpa: Guaymuras.

Barre, M. (1983). Ideologías Indigenistas y Movimientos Indios. México: Siglo XXI.

Beyer, Peter (1994). Religion and Globalization. London: Sage.

Bonfil Batalla, G. (1981). Utopía y revolución. México: Nueva Imagen. 
Bourdieu, Pierre (1971). Genèse et structure du champ religieux, Revue Française de Sociologie, XII (2): 295-334,

Bourdieu, Pierre (1993). Cosas dichas. Barcelona: Gedisa.

Cantón, Manuela (1998). Bautizados en fuego. Vermont: Plumsock Mesoamerican Studies-CIRMA.

Cantón, Manuela (1999) Ética protestante del trabajo y contextos de conversión. Max Weber en América Latina. En Religión y Cultura. S. Rodríguez Becerra, Coord. Sevilla: Consejería de Cultura.

Cantón, Manuela (2001). La razón hechizada. Teorías antropológicas sobre la religión. Barcelona: Ariel.

Chapman, Anne (1985). Los hijos del copal y la candela. Ritos agrarios y tradición oral de los lencas de Honduras. México: UNAM.

Cruz Oliva, J. A. (1998) La identidad colectiva hondureña. Tesis Doctoral. Univ. País Vasco. Dep. Ciencias Sociales y de la Comunicación.

Cruz Sandoval, F., Coord. (1984). América Indígena, XLIV: 421-612.

De Andrade Coelho, R. (1986). Los negros caribes de Honduras. Tegucigalpa: Guaymuras.

Díaz Polanco, H. (1991). Autonomía Regional. La autodeterminación de los pueblos indios. México: Siglo XXI.

Euraque, Darío (1996). Estado, poder, nacionalidad y raza. Tegucigalpa: Edit. Subirana.

Flores, Lázaro (1996). El Siglo Nuevo. Un movimiento mesiánico de carácter milenarista entre los Chortís de Honduras y Guatemala, Revista Cambio UPNFM: 44-50.

Flores, L y Griffin, W. (1991) Dioses, héroes y hombres en el universo mítico de los pech. El Salvador: UCA.

Flores, Lázaro et al. (1995). Los Chortí de Honduras. Apuntes Etnográficos. Tegucigalpa: Univ. Pedagógica Nac. Francisco Morazán.

Gil Tébar, Pilar (1999). Recreando la palabra. La teología india y la pastoral indígena. En Religión y Cultura, S. Rodríguez Becerra, Coord. Sevilla: Consejería de Cultura.

Girard, R. (1949). Los chortís ante el problema maya. México: Editorial Cultura.

Gómez, Águeda (2003). Resistencias colectivas entre los grupos indígenas de selva húmeda tropical en Latinoamérica. En Globalización, resistencia y negociación en América Latina. B. Pérez y G. Dietz, Eds. Madrid: Catarata.

Hassemann et al. (1996). Los indios de Centroamérica. Madrid: Mapfre.

Lanza, A. et al. (1986). Los Pech. Tegucigalpa: Guaymuras.

Lara Pinto, Gloria (1997). Educación de Adultos en contextos Indígenas en Honduras. Tegucigalpa: Secretaría de Educación-GTZ.

Mackay, F. (2001). Guía para los derechos de los pueblos indígenas en el sistema interamericano de DH. En http://www.forestpeoples.org/documents. Accedido 10 de Diciembre de 2006. .

Mackay, F. (2002). Enfrentándose a los errores del pasado. Pueblos Indígenas y áreas protegidas. En http://www.forestpeoples.org/documents. Accedido 10 de Diciembre de 2006. 
Mackay, F. y Colchester, Marcus (2006). Forjando un espacio de negociación. Pueblos indígenas, representación colectiva y el derecho al consentimiento. En http:// www.forestpeoples.org/documents. Accedido 10 de Diciembre de 2006.

Martínez, Adalid (1997). La fuerza de la sangre chortí. San Pedro Sula: Centro Editorial Industrias Imet.

Marzal, M. (1985). El sincretismo iberoamericano. Lima: PUCP.

Mendoza, Brenda (2001). La desmitologización del mestizaje en Honduras. Mesoamérica, 42: 256278.

Menéndez, Eduardo (2002). La parte negada de la cultura. Barcelona: Bellaterra,

Monreal, Pilar (2003). De campesinos a indígenas. Tierra y cultura en los discursos del desarrollo. En Globalización, resistencia y negociación en América Latina. B. Pérez y G. Dietz, Eds. Madrid: Catarata.

Moreno, Isidoro (1991). Identidades y rituales: Estudio Introductorio, En Antropología de los pueblos de España. Prat, Martínez, Moreno y Contreras, Eds. Madrid: Taurus.

Morris, Bryan (1995). Introducción al estudio antropológico de la religión. Barcelona: Paidós.

Mortensen, Lena (2001). Las dinámicas locales de un patrimonio global. Arqueoturismo en Copán. Mesoamérica, 42: 104-134..

Mosquera, A. (1984). Los chortís de Guatemala. Guatemala: Editorial Universitaria.

Murillo Chaverri, Carmen (1996). Antropología e identidades en Centroamérica. San José: Pub. Univ. Costa Rica.

Newson, Linda (1992). El costo de la conquista. Tegucigalpa: Guaymuras.

Newson, Linda (1998a). Culturas y ambientes indígenas. En Lecturas de Historia de Honduras. Oscar Zelaya, Comp. Tegucigalpa: UPNFM..

Newson, Linda (1998b). Variaciones regionales en el impacto del dominio colonial español en las poblaciones indígenas de Honduras y Nicaragua. En Lecturas de Historia de Honduras. Oscar Zelaya, Comp. Tegucigalpa: UPNFM

Pérez, Beatriz y Dietz, Gunther, Eds. (2003). Globalización, resistencia y negociación en América Latina. Madrid: Catarata.

Rivas, Ramón (1993). Pueblos indígenas y garífunas de Honduras. Tegucigalpa: Guaymuras.

Sanchiz Ochoa, Pilar (1998). Evangelismo y poder. Guatemala ante el nuevo milenio. Sevilla: Univ. Sevilla.

Sanchiz Ochoa, Pilar (1999). Pluralismo religioso en América Latina. En Religión y Cultura, S. Rodríguez Becerra, Coord. Sevilla: Consejería de Cultura.

Tojeira, J. (1982). Los xicaques de Yoro. Tegucigalpa: Guaymuras.

Wallace, Anthony (1972). "Milenarismo" ; "Nativismo"; y "Revivalismo", En Enciclopedia Internacional de las Ciencias Sociales. D. Sills, Ed. Madrid: Aguilar.

Wisdom, Charles (1961). Los chortís de Guatemala. Guatemala: Edit. Pineda Ibarra.

AIBR. Revista de Antropología Iberoamericana. www.aibr.org

Volumen 2, Número 1. Enero-Abril 2007. Pp. 19-42

Madrid: Antropólogos Iberoamericanos en Red. ISSN: 1695-9752 